\title{
POMEN CENTRA ŠOLSKIH IN OBŠOLSKIH DEJAVNOSTI (CŠOD) PRI POUKU IN TERENSKEM DELU GEOGRAFIJE
}

\author{
Špela Odar ${ }^{*}$
}

Izvleček

$U D K$ 371.388:373.3(497.4)

Prispevek obravnava program življenja v naravi za osnovno šolo, in sicer 5., 6. in 7. razred. Posebej so predstavljene geografske teme, s katerimi se v tednu dni, ki je na razpolago, srečajo učenci pri pouku in na terenu $v$ enem izmed trinajstih domov $v$ Sloveniji.

Ključne besede: življenje v naravi, projektni teden

$$
\text { GEOGRAPHY IN SLOVENIAN FIELD STUDY CENTRES }
$$

\section{Abstract}

The paper represents a program written for a "week in nature" for students of 5th, 6th and 7th primary school classes. Primary stress is given to the geographic themes, field work and theory, which are presented in a weekly course in one of 13 field studies centres in Slovenia.

Key words: life in nature, project week * Prof., Center šolskih in obšolskih dejavnosti, Dom Bohinj, Ribčev Laz 63, 4265 Boh. Jezero,
Slovenija 


\section{UVOD}

Terensko delo ima pri pouku geografije poseben pomen. Po učnem načrtu naj bi se učenci udeležili najmanj ene celodnevne ekskurzije in najmanj dveh krajših terenskih vaj $\mathrm{v}$ posameznem šolskem letu. Vsebina je lahko samo geografska, lahko pa interdisciplinarna.

Šole lahko organizirajo ekskurzije in naravoslovne dni samostojno, lahko pa se odločijo za enega izmed programov, ki jih izvajajo domovi Centra šolskih in obšolskih dejavnosti.

Prednosti izbire tedenskega programa omogočajo učencem naslednje:

- prebivanje v naravi, kjer učenci s pomočjo pedagoških delavcev in inštruktorjev s posebnimi znanji doživijo pristni stik z naravo,

- $\quad$ spoznavanje z različnimi bivalnimi okolji, navadno v regiji, ki je oddaljena od domače in zato toliko bolj različna od nje,

- pridobivanje praktičnih znanj in izkušenj, različnih spretnosti, spoznavanje $\mathrm{z}$ reševanjem in razumevanjem zastavljenih problemov,

- dopolnjevanje znanja iz različnih tem, ki so del učnega načrta,

- učenje strpnosti in sodelovanja ob skupnem delu in sprostitvi,

- vzgajanje za odgovornost lastne varnosti in zdravja,

- domovi so opremljeni s potrebno tehnično opremo, nujno za terensko delo.

Prav tako so na razpolago t.i. dnevni centri, ki jih učenci lahko obiščejo v okviru naravoslovnih dni. Zaposleni $\mathrm{v}$ dnevnih centrih še posebej dobro poznajo problematiko in posebnosti centra, s čimer seznanijo učence.

\section{PREDSTAVITEV CŠOD}

\section{Začetki organiziranosti}

CŠOD je javni zavod, ki ga je oktobra 1992 ustanovila Vlada Republike Slovenije in mu dala v uporabo in upravljanje nekatere bivše vojaške objekte in njim pripadajoča zemljišča. 


\section{Domovi}

Trenutno deluje po Sloveniji 13 domov, kjer se izvaja tedenski program, dva sta $\mathrm{V}$ investicijskem programu za leto 1998/99. Poleg tega deluje tudi 8 dnevnih centrov. Domovi se nahajajo po Sloveniji, kar omogoča seznanitev učencev z različnimi naravno-geografskimi pokrajinami in s tem z njihovimi značilnostmi.

\section{Karta 1: Domovi CŠOD}

Slovenian Field Study Centres

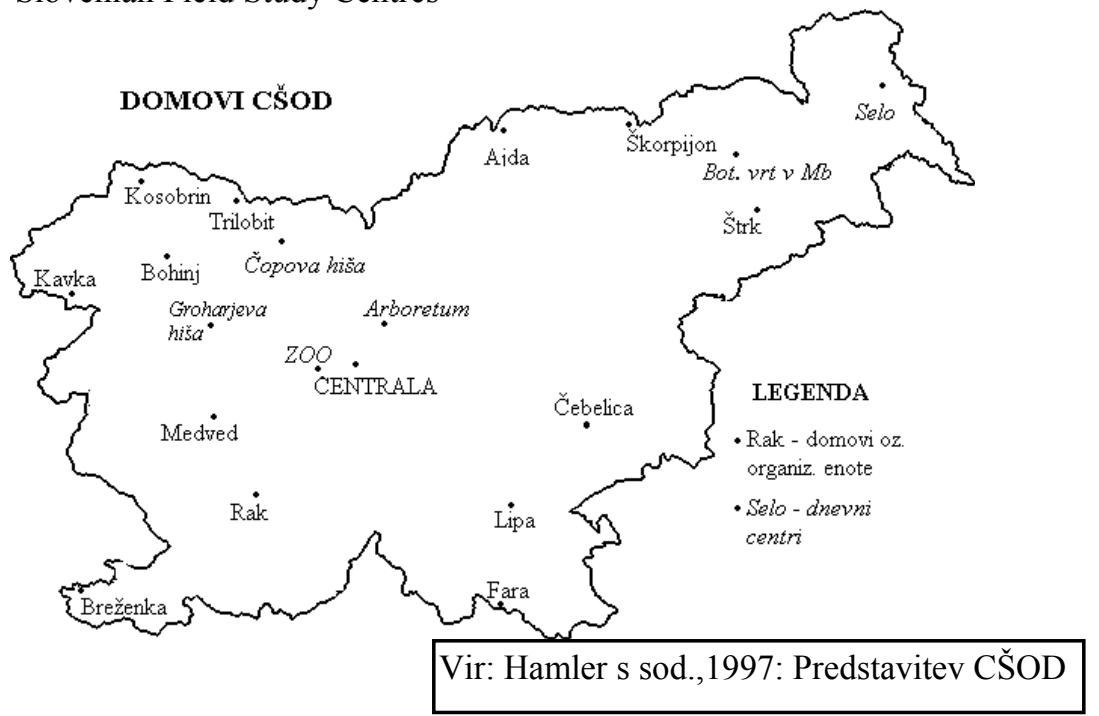

\section{Domovi CŠOD}
1. Ajda na Libeličah
2. Bohinj
3. Breženka v Fiesi
4. Čebelica v Dolenji vasi pri Čatežu
5. Fara v Fari - občina Kostel
6. Kavka na Livških Ravnah
7. Kosobrin v Kranjski Gori
8. Lipa v Črmošnjicah
9. Medved na Medvedjem Brdu
10. Rak v Rakovem Škocjanu
11. Škorpijon na Kozjaku
12. Strk v Spuhlji
13. Trilobit na Javorniškem Rovtu 


\section{PROGRAMI, KI SE IZVAJAJO V OKVIRU CŠOD}

$\mathrm{V}$ Šolskih razgledih je vsako leto $\mathrm{v}$ maju objavljen javni razpis programskih in prostorskih zmogljivosti za prihodnje šolsko leto. Programi potekajo v domovih med šolskim letom, to je od 1 . septembra do 30 . junija.

\section{Šole se lahko odločajo med naslednjimi programi:}

1. Življenje v naravi (ŽvN) za 5., 6. in 7. razred OŠ,

2. ŽvN z začetnim naravoslovjem za 3. in 4. razred OŠ,

3. ŽvN za učence s posebnimi potrebami za 7. razred OŠ s prilagojenim programom,

4. zimski športni teden za 5., 6, in 7. razred OŠ in SS̆,

5. taborjenje in preživetje v naravi ter obvezne izbirne vsebine za SS̆,

6. projektni tedni za gimnazije,

7. naravoslovni in kulturni dnevi $\mathrm{v}$ dnevnih centrih,

8. domske zmogljivosti.

Geografske teme se obravnavajo pri dveh programih:

1. Program življenja v naravi, ki traja pet dni od ponedeljka do petka in je deljen na obvezni učni del (naravoslovne teme, veščine in športne dejavnosti), usmerjeni prosti čas in dejavnosti učencev, namenjene opravilom iz vsakdanjega življenja.

Osnovni sklop vzgojno-izobraževalnega dela programa je enak na vseh domovih, a vedno krajevno obarvan. Približno $80 \%$ obveznega programa poteka kot praktično delo, ostalo pa je teorija, ki je potrebna za izvajanje praktičnih vsebin. Program je sestavljen iz naslednjih sklopov:

- naravoslovje - 16 ur

osnovne teme, katerih cilji se prilagajajo razredu in letnemu času so:

$\begin{array}{ll}\text { gozd } & \cdot \begin{array}{l}\text { onesnaženost zemlje, vode ali zraka } \\ \text { vremenoslovje } \\ \text { kamnine }\end{array} \\ \end{array}$

športno-rekreativna in večerna animacija - 14 ur

jutranja gimnastika

pohodništvo lokostrelstvo

pozimi igre na snegu

življenje v naravi - $10 \mathrm{ur}$ 
- vozli

- ognji in ognjišča

nevarnosti narave

- prehrana v naravi

- zavetišča

- geografska in topografska orientacija

V 7. razredu je programu dodana še prva pomoč na račun zmanjšanja tem iz ostalih sklopov.

Poleg tega ima vsak dom na razpolago 10 pedagoških ur za t.i. referenčne dejavnosti, ki omogočajo učencem spoznati krajevne posebnosti, ki so povezane z lego in opremljenostjo doma.

V prostočasnih dejavnostih pa učenci izbirajo med dejavnostmi, ki jih zanimajo. Dejavnosti vodijo učitelji inštruktorji in učitelji spremljevalci.

SHEMATSKI PREGLED ŠTEVILA PEDAGOŠKIH UR PO PODROČJIH GLEDE NA RAZRED

\begin{tabular}{|c|c|c|c|c|c|c|}
\hline \multirow{2}{*}{$\begin{array}{l}\text { Razred } \\
\text { Področje }\end{array}$} & \multicolumn{2}{|c|}{ 5. razred } & \multicolumn{2}{|c|}{ 6. razred } & \multicolumn{2}{|c|}{ 7. razred } \\
\hline & št. PU & $\%$ & št. PU & $\%$ & št. PU & $\%$ \\
\hline Naravoslovje & 16 & 32 & 16 & 32 & 10 & 20 \\
\hline - od tega geografske teme & 9 & 14 & 7 & 11 & 7 & 11 \\
\hline $\begin{array}{l}\text { Športno- rekreativna dejavnost } \\
\text { in večerna animacija }\end{array}$ & 14 & 28 & 14 & 28 & 12 & 24 \\
\hline Življenje v naravi & 10 & 20 & 10 & 20 & 8 & 16 \\
\hline - od tega geografske teme & 2 & 3 & 2 & 3 & 2 & 3 \\
\hline Prva pomoč & & & & & 10 & 20 \\
\hline Referenčne dejavnosti & 10 & 20 & 10 & 20 & 10 & 20 \\
\hline $\begin{array}{|lll|}\text { Skupaj obveznih } & \text { vsebin } \\
\text { tedensko } & & \\
\end{array}$ & 50 & 100 & 50 & 100 & 50 & 100 \\
\hline Prostočasne dejavnosti & 13. & & 11. & & 15. & \\
\hline SKUPAJ & 63. & & 63. & & 63. & \\
\hline
\end{tabular}


Slika 1: Delež geografije v programu ŽvN za 5. razred

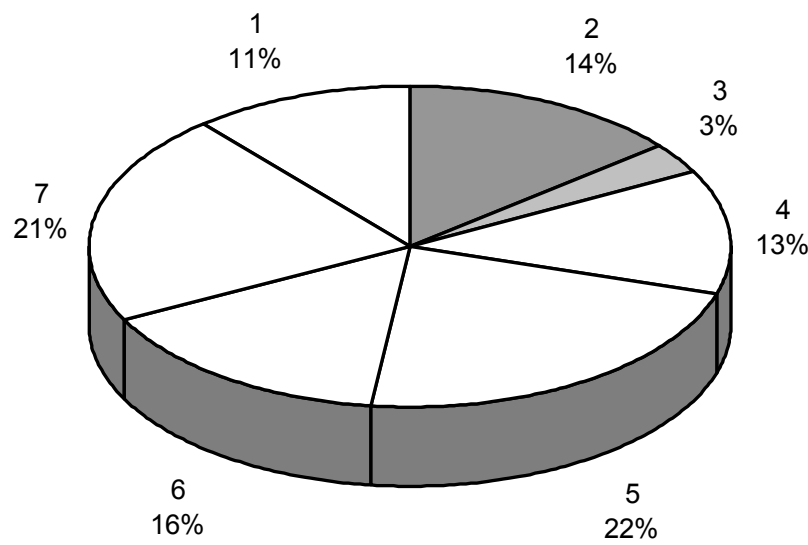

1. ure naravoslovja

2. geografske teme pri urah naravoslovja

3. geografske teme pri urah življ. v naravi

Slika 2 : Delež geografije v programu ŽvN za 6. razred

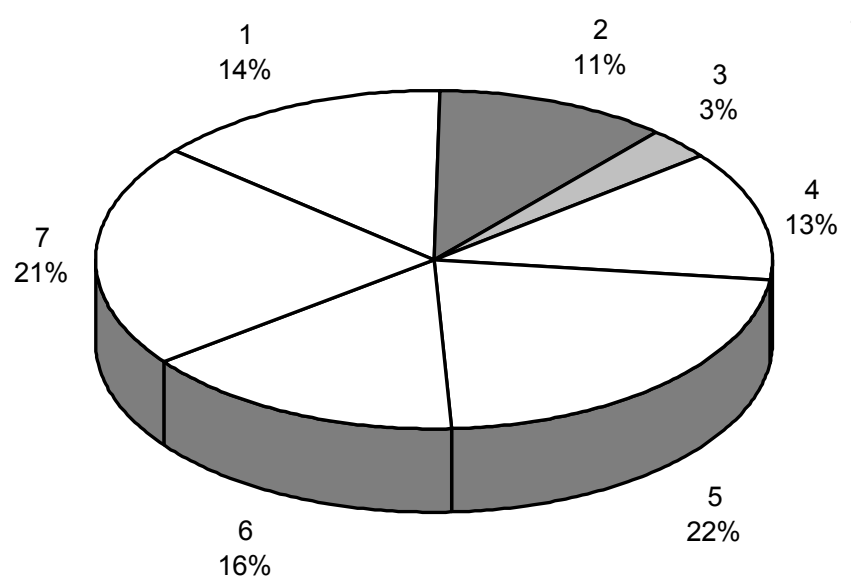

4. ure življenja v naravi

5. športnorekreativna dejavnost referenčne dejavnosti

7. prostočasne dejavnosti

Vir: Hamler J. s sod., 1997: Program.

V 7. razredu je delež geografskih tem enak deležu v 6. razredu. 
2. Projektni teden za gimnazije. Tematiko projektnih nalog lahko določi šola ali pa jo predlagajo učitelji naravoslovja, zaposleni na domu. Na razpolago je navadno 1620 pedagoških ur, v preostalem času pa potekajo športne dejavnosti in del programa življenja $\mathrm{v}$ naravi. Ravno pri tem programu je lahko tematika naloge izključno geografska. Pri tem mora biti profesor geografije navzoč vsaj kot spremljevalec skupine, še bolje pa je, da vsebino in cilje naloge predlaga zaposlenim učiteljem naravoslovja $\mathrm{v}$ domu.

Poleg tega pa se šole lahko odločijo tudi za druge programe:

Pri programu zimskega športnega tedna prevladuje učenje smučanja (smučanje v vrsti) - število ur je odvisno od dogovora s skupino in možnosti. V domovih je možna izposoja opreme za alpsko smučanje in smučarske teke. Dejavnosti v popoldanskem in večernem času se usklajujejo z željami in potrebami šole.

Program taborjenja in preživetja $\mathbf{v}$ naravi ter obvezne izbirne vsebine za srednje šole je navadno sestavljen po željah šole in možnostih, ki jih nudi dom in okolica. Navadno prevladujejo športne dejavnosti in program preživetja $\mathrm{v}$ naravi združen $\mathrm{s}$ tematikami, ki so aktualne $\mathrm{v}$ današnjem času, npr. problemi onesnaževanja, zasvojenosti ipd.

Pri vseh programih je poudarek na terenskemu delu, tako da učenci in dijaki spoznavajo, raziskujejo in se učijo v naravi. Domovi pa so poleg tega opremljeni s potrebno opremo, kot so mikroskopi, lupe, kompasi, daljnogledi, naprave za merjenje "vremena«, kemikalije za ugotavljanje onesnaženosti vode, loki, ter z opremo, ki je potrebna za izvajanje referenčnih dejavnosti - smučarska oprema za alpsko smučanje in tek na smučeh (dopolnjuje se z opremo, ki jo udeleženci prinesejo s seboj). 


\section{GEOGRAFSKE TEME, KI SO VKLJUČENE V OSNOVNI SKLOP PROGRAMA ŽVN}

\section{Geografsko-topografska orientacija (2 uri)}

sodi v sklop življenja v naravi, ki jo vodijo učitelji inštruktorji. Cilji se razlikujejo glede na starost oz. razred, ki ga učenci obiskujejo.

Tako v 5. razredu učenci

- ponovijo različne načine določanja strani neba $\mathrm{z}$ uro in senco,

- spoznajo se s kartami različnih meril,

- ocenjujejo razdalje med kraji in računajo višine vrhov,

- naučijo se uporabljati kompas.

\section{6. razredu}

- spoznajo poleg zemljevidov različnih meril še topografske znake,

- naučijo se branja izohips in pravilnega orientiranja s karto,

- ponovijo delovanje kompasa in se naučijo ohraniti smer gibanja $z$ njegovo pomočjo,

- ogledajo si in potem narišejo zemljevid okolice doma, kjer uporabijo topografske znake.

\section{7. razred}

- ponovno ponovijo delovanje in uporabo kompasa,

- spoznajo se s pojmom azimut in koordinate in se gibajo s pomočjo topografske karte,

- spoznajo višinomer in njegovo uporabo,

- posebnosti, ki so v naravi in okolici, doma vrišejo v zemljevid.

V sklopu naravoslovja pa so z geografijo povezane naslednje teme:

\section{Kamnine (3 ure, $v$ 7. razredu - 2 uri)}

V 5. razredu učenci spoznajo povezanost med kamnino, prstjo in organizmi. Pri tem naj bi učenci

- spoznali kamnine glede na nastanek,

- opazovali in določili pomembne kamnine $\mathrm{v}$ okolici doma ter razložili njihov nastanek,

- spoznali dejavnike, ki omogočajo nastanek prsti, in primerjali različne prereze tal, 
- ugotavljali kislost oz. bazičnost tal in odvisnost od kamnine,

- v zimskem času pa je večji poudarek na mineralih in fosilih ter njihovem nastanku.

V 6. razredu učenci spoznajo uporabnost in koristnost kamnin :

- ugotovijo, katere kamnine so bile uporabljene pri gradnji doma in ostalih objektov v okolici,

- primerjajo kamnine $\mathrm{v}$ starejših in novih objektih ter ugotavljajo razlike,

- sklepajo, zaradi katerih lastnosti se kamnine uporabljajo,

- obiščejo morebitna mesta pridobivanja kamnin (peskokopi, gramoznice...).

V 7. razredu učenci povezujejo geološko zgradbo in oblikovanost površja. Pri tem:

- opazujejo okolico, kjer ugotavljajo reliefne značilnosti in geološko sestavo tal,

- primerjajo različne kamnine glede odpornosti,

- seznanijo se z osnovami nastanka prelomov in povezanosti s potresi,

- ugotavljajo dejavnike oblikovanja in preoblikovanja površja.

\section{Onesnaženost (2 uri)}

Onesnaženost zemlje v okolici doma in varstvo pred onesnaževanjem se obravnava v 5. razredu:

- učenci si ogledajo in opišejo odpadke v okolici doma,

- ločijo med razgradljivimi in nerazgradljivimi odpadki in sklepajo o prednosti prvih pred drugimi,

- ugotavljajo, koliko odpadkov nastane $\mathrm{v}$ enem dnevu bivanja $\mathrm{v}$ domu na enega učenca,

- pripravijo predlog reciklaže teh odpadkov.

Onesnaženost vode v okolici in varstvo je tematika v 6. razredu:

- učenci spoznajo osnovne vire onesnaževanja vode v okolici doma,

- ugotavljajo vsebnost nitratov in sklepajo, od kod bi lahko izvirali,

- poiščejo načine izboljšanja kakovosti pitne vode oziroma možnosti zavarovanja čistih voda,

- $\quad$ spoznajo pojem zajetij in vodnih rezervatov,

- $\quad$ spoznajo organizme, ki žive v različno onesnaženih vodah.

Onesnaženost zraka in varstvo pa je snov, ki jo obravnavamo v 7. razredu:

- učenci ugotovijo in popišejo vire onesnaževanja zraka v okolici doma,

- spoznajo nevarnosti, ki prizadenejo kakovost zraka, pojav tople grede, ozonske luknje in kislega dežja,

- spoznajo lišaje kot bioindikatorje onesnaženosti zraka. 


\section{Vremenoslovje (2 uri)}

V 5. razredu se učenci seznanijo z osnovnimi vremenskimi meritvami:

- merijo temperaturo, vlažnost, padavine, zračni tlak in hitrost vetrov, vremenske podatke vpisujejo $\mathrm{v}$ tabelo in jih nato interpretirajo,

- klasificirajo vetrove $\mathrm{v}$ okolici doma.

V 6. razredu je pri vremenoslovju poudarek na vrstah oblakov in napovedovanju vremena:

- ponovijo, na podlagi česa so napovedovali vreme naši predniki,

- merijo in beležijo osnovne vremenske dejavnike,

- poskušajo napovedati vreme za naslednji dan glede na izmerjene podatke,

- spoznajo vrste oblakov, jih opazujejo in skicirajo ter povezujejo obliko oblakov in vreme,

- ugotavljajo, kako vreme vpliva na počutje človeka.

\section{Opazovanje zvezdnega neba ( 2 uri)}

V 5. razredu učenci spoznavajo Osončje, Rimsko cesto in Luno

- naučijo se razlikovati planet od zvezde,

- vedo, kaj je Rimska cesta in kje leži Zemlja v Galaksiji,

- spoznavajo Lunino površje,

- razumejo nastanek Luninih men ter Luninih in Sončevih mrkov,

- opazujejo kroženje Lune okrog Zemlje,

- opazujejo vidne planete in izdelajo skico manjšega dela zvezdnega neba.

V 7. razredu pa učenci spoznavajo glavna ozvezdja z vodilnimi zvezdami:

- spoznajo različne teorije o nastanku vesolja, zvezd in planetarnih sistemov,

- spoznajo metode določevanja razdalj v vesolju,

- ponovijo nastanek letnih časov na planetih,

- spoznajo zgodovino odkritij Urana, Neptuna in Plutona,

- po možnosti izdelajo lastno zvezdno karto. 


\section{Kako človek spreminja naravno okolje (1 ura)}

Učenci 7. razreda spoznajo posledice urbanizacije okolja:

- ogledajo si bližnje naselje ter ugotavljajo spremembe v naravnem okolju, ki jih je povzročil človek z urbanizacijo,

- preučujejo posledice urbanizacije za naravno okolje,

- poiščejo nadaljnje načine urbanizacije, ki bi naravno okolje čim manj prizadeli.

\section{SKLEP}

Center šolskih in obšolskih dejavnosti s programi, ki se izvajajo v domovih, prispeva $\mathrm{k}$ boljšemu razumevanju geografije, saj učenci v naravi vidijo in sami poskusijo, izmerijo in otipajo tisto, o čemer se učijo v šoli.

Program življenja v naravi za učence 5.,6. in 7. razreda, ki se po domovih največ izvaja je bil sestavljen v maju 1997 in še ni povsem dokončen. Pri pripravi naravoslovnega dela programa so bili $\mathrm{v}$ večini profesorji biologije, zato je tudi program precej biološko obarvan. V zadnjem času pa se tudi ob sodelovanju s tujino Center zaveda, da bi bilo lahko geografskih tem še več in da bi bile lahko tudi bolj poglobljene, mogoče ne toliko v osnovnem sklopu, kot med referenčnimi dejavnostmi posameznih domov, tako da bi učenci lahko še bolje spoznali mikroregijo, v kateri preživljajo življenje v naravi. Prav zato pa si bomo morali tudi sami prizadevati, tako zaposleni kot tudi vsi učitelji in profesorji geografije, ki bodo obiskali enega izmed centrov kot spremljevalci svojih učencev.

Prav tako obstaja možnost boljšega sodelovanja s posameznimi domovi v okviru naravoslovnih dni in enodnevnih ali dvodnevnih ekskurzij.

Terensko delo ima pri pouku geografije poseben pomen. Po programu se izvaja $\mathrm{v}$ sklopu naravoslovnih dni in ekskurzij, prav tako pa tudi v šoli v naravi, kadar se šola za tak program odloči.

V Sloveniji že od leta 1992 deluje javni zavod imenovan Center šolskih in obšolskih dejavnosti (CŠOD), ki izvaja različne tedenske programe trenutno $\mathrm{v}$ trinajstih domovih, poleg tega pa je na razpolago še osem dnevnih centrov, ki jih šole obiskujejo ob naravoslovnih in kulturnih dnevih.

Največ šol se odloča za program življenja v naravi, ki zajema tako športne dejavnosti, veščine potrebne za življenje $\mathrm{v}$ naravi, kot tudi naravoslovne dejavnosti. Pri naravoslovju prevladujejo teme iz biologije, vključena je tudi geografija. 
Geografske tematike, vključene v program za 5., 6. in 7. razred osnovne šole, zajemajo področja varstva okolja (onesnaženost zraka, vode in tal ter varstvo), geomorfologije (značilnosti pokrajine), pedogeografije (nastanek prsti), klimatogeografije (osnovne vremenske meritve), matematične geografije (gibanja Zemlje in ostalih planetov, opazovanje zvezdnega neba), prav tako pa ne manjka geografska in topografska orientacija. Poudarek je na čim večjem samostojnem delu učencev na terenu.

Srednje šole se lahko odločijo za t.i. projektni teden, kjer se tematika določa tudi glede na želje šole, zato so naloge lahko povsem geografske.

Kljub temu da program življenja v naravi že vključuje določene geografske teme, bi si morali geografi prizadevati za vključevanje novih in zanimivih vsebin s svojega področja. Prav tako bi bilo potrebno izboljšati sodelovanje s posameznimi domovi pri naravoslovnih dnevih in enodnevnih ali dvodnevnih ekskurzijah.

\section{LITERATURA}

1. Hamler J. s sod., 1997: Predstavitev Centra šolskih in obšolskih dejavnosti. Interno gradivo CŠOD, izdano ob 5. obletnici delovanja Centra. Ljubljana.

2. Hamler J. s sod., 1997: Program življenja v naravi za osnovno šolo. Interno gradivo CŠOD. Ljubljana.

3. Kunaver J. s sod., 1998: Učni načrt: Geografija. Nacionalni kurikularni svet. Področna kurikularna komisija za osnovno šolo, Predmetna kurikularna komisija za osnovno šolo, Državni izpitni center. 


\section{GEOGRAPHY IN SLOVENIAN FIELD STUDY CENTRES}

\section{Summary}

Field work has a special meaning in geography lessons. The students can experience it in field days for natural science, or on excursions. They can also attend a "week in nature", if the school accepts this special programme.

Since 1992 in Slovenia it has been possible to attend one of seven different programs in a public institution called the Centre for School and Outdoor Activities. There are 13 such centers with accommodation facilities, and eight centers for daily visitors throughout Slovenia.

Weekly programs contain sport activities, survival skills, as well as some natural science. Biology prevails here, but there are also geographic themes.

In the program "life in nature" for 5th, 6th and 7th primary school classes, the following themes exist: geographic and topographic orientation, geology, environmental studies (pollution of soil, water and air), geomorphology (landscape characteristics), meteorology and astronomy.

Secondary schools can choose what is known as a "project week", where the theme may be chosen in advance by geography teachers.

Although geography is a part of the programme in the schools in nature, there are still chances to have more geographic themes, especially those connected with regions where the students are staying. 